\title{
Industrial wastewater treatment through bioaugmentation
}

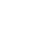

\author{
E. Raper ${ }^{a}$, T. Stephenson ${ }^{a}$, D. R. Anderson ${ }^{\text {b. }}$, R. Fisher ${ }^{\text {b }}$, A. Soares ${ }^{\text {a }}$.
}

${ }^{\text {a }}$ Cranfield University Water Sciences Institute, Cranfield University, Cranfield, MK43 0AL, UK. e.raper@cranfield.ac.uk, T.Stephenson@.cranfield.ac.uk, a.soares@cranfield.ac.uk

${ }^{\mathrm{b}}$ Tata Steel, Group Environment, Swinden Technology Centre, Rotherham, S60 3AR, UK. david.anderson@tatasteel.com, ray.fisher@tatasteel.com

\section{$\underline{\text { Abstract }}$}

Bioaugmentation of activated sludge processes through the addition of microorganisms is employed with the aim of enhancing treatment, in particular the removal of priority pollutants. With industrial wastewaters, studies have covered target pollutants including ammonia and polycyclic aromatic hydrocarbons (PAHs): compounds that are regulated around the globe. However, bioaugmentation is a technique that has been associated with doubt in regard to its ability to benefit treatment processes. Failure of bioaugmentation has been reported to be associated with numerous factors that include the growth rate being lower than the rate of washout, insufficient inoculum size and substrate availability. Limitations of bioaugmentation can be overcome through techniques that include increased inocula dosing, pre-acclimatisation of inocula in side-stream reactors, addition of nutrients and surfactants and application of sufficient acclimatisation periods. Surveys of the literature show that a key area for further research should be towards acquiring a better understanding of the degradation pathways where bioaugmentation is applied. There also remains a need to undertake bioaugmentation efficacy studies at full scale with test and control streams. Further reporting on the economic viability of the technique is also necessary.

Keywords: Bioaugmentation; industrial wastewater; nitrogen; polycyclic aromatic hydrocarbons; phenol 


\section{Introduction}

32 Industrial wastewaters account for a large proportion of pollution in freshwater systems and 33 are therefore regulated across the globe. For example, in Europe, industrial wastewaters are regulated under the Industrial Emissions Directive (IED) whilst in the United States they are regulated under the Clean Water Act (European Commission, 2015b; US.EPA, 2015). Under the IED, the compounds included in the regulation vary for each industrial process and are reported along with the associated emission limits in the best available techniques reference document (BREF) (European Commission, 2011). An activated sludge process (ASP) has been identified as the best available technique (BAT) to meet the required emission limits

40 (Table 1) for a number of such wastewaters. This includes wastewaters from the milk and food industry, waste gas treatment, refinery of mineral oil and gas, iron and steel coke processing and glass manufacturing (European Commission, 2003, 2006, 2012, 2013a, 2013b, 2014, 2015a).

The suspended microbial mass in an ASP is responsible for the biodegradation of organic 46 compounds via the metabolic reactions of the bacteria (Zhang et al., 2014a). Many industrial wastewaters contain a mixture of compounds that are recalcitrant and others that may be toxic; such wastewaters therefore have the potential to persist in effluents after an ASP. It is thus necessary to establish treatment methods which can cope with the complex mixture of compounds typically associated with industrial wastewaters. Bioaugmentation, the addition of supplementary microorganisms with their associated biodegradation capacities, may allow for the improved performance of ASPs (Semrany et al., 2012). 
Table 1: Industrial Emission Directive emission limits for wastewaters for which an activated sludge process is recognised as the best available technique.

\begin{tabular}{|c|c|c|c|}
\hline Wastewater origin & BAT emission limit (mg/L) & Reference & \\
\hline \multirow{3}{*}{$\begin{array}{l}\text { Produced Water (Oil } \\
\text { and gas wastewater) }\end{array}$} & Hydrocarbon oil index: $0.1-2.5$ & \multirow{3}{*}{$\begin{array}{l}\text { (European } \\
\text { 2014) }\end{array}$} & \multirow[t]{3}{*}{ Commission, } \\
\hline & COD: $30-125$ & & \\
\hline & TN: $1-25$ & & \\
\hline \multirow{5}{*}{$\begin{array}{l}\text { Food and Milk: } \\
\text { e.g. Raw dairy, Cheese, } \\
\text { Mixed dairy, palm oil } \\
\text { mill effluent. }\end{array}$} & Oil and grease: $<10$ & \multirow{5}{*}{$\begin{array}{l}\text { (European } \\
2006)\end{array}$} & \multirow[t]{5}{*}{ Commission, } \\
\hline & COD: $<125$ & & \\
\hline & $\mathrm{BOD}_{5}:<25$ & & \\
\hline & $\mathrm{TN}:<10$ & & \\
\hline & TP: $0.4-5$ & & \\
\hline \multirow[t]{4}{*}{ Glass manufacturing } & COD: $<5-130$ & \multirow{4}{*}{$\begin{array}{l}\text { (European } \\
2012 \text { ) }\end{array}$} & \multirow[t]{4}{*}{ Commission, } \\
\hline & Total hydrocarbons: $<15$ & & \\
\hline & Ammonia $\left(\right.$ as $\left.\mathrm{NH}_{4}\right):<10$ & & \\
\hline & Phenol: $<1$ & & \\
\hline \multirow{6}{*}{$\begin{array}{l}\text { Coke } \\
\text { wastewater: }\end{array}$} & COD: $<220$ & \multirow{6}{*}{$\begin{array}{l}\text { (European } \\
\text { 2013a) }\end{array}$} & \multirow[t]{6}{*}{ Commission, } \\
\hline & $\mathrm{BOD}_{5}:<20$ & & \\
\hline & $\mathrm{SCN}:<4$ & & \\
\hline & PAHs*: 0.05 & & \\
\hline & Phenols: 0.5 & & \\
\hline & $\mathrm{TN}:<15-50$ & & \\
\hline
\end{tabular}

*Sum of fluoranthene, benzo[b]fluoranthene, benzo[k]fluoranthene, benzo[a]pyrene, indeno[1,2,3-cd]pyrene and benzo[g,h,i]perylene 
Industrial wastewaters represent some of the most challenging waters requiring treatment and therefore offer insight into some of the more complex situations in which bioaugmentation may be implemented. Benefits may include more stable operating conditions, better flocculation characteristics, decreased start-up times, resistance to shock loads and better cold weather performance (Stephenson and Stephenson, 1992; Van Limbergen, Top and Verstraete, 1998; Guo et al., 2009; Bartrolí, Carrera and Pérez, 2011; Qu et al., 2011). Bioaugmentation has been reported to be unpredictable (Boon et al., 2000), however, a number of factors have been highlighted as impacting successful bioaugmentation including: strain selection, addition and maintenance techniques and knowledge of the molecular biology and the capabilities of commercial products (Stephenson and Stephenson, 1992; Van Limbergen, Top and Verstraete, 1998; Thompson et al., 2005; Herrero and Stuckey, 2014).

\section{Strain selection}

The selection of a suitable strain is essential to the success of bioaugmentation. The selected strain(s) must be able to withstand the environmental conditions imposed on them within a treatment process including; temperature, $\mathrm{pH}$, dissolved oxygen, nutrient availability, toxicity and microbial pressures (Bitton, 2011). It is well recognised that, without an understanding of the conditions within the treatment process, bioaugmentation is likely to fail due to the poor survival of the inoculum and/or competition from indigenous microbial populations (Stephenson and Stephenson, 1992; More et al., 2010). The selection and isolation of a strain from the indigenous population has become, progressively, the favoured approach as this increases the likelihood of success as the strain is already adapted to survival in the selected environment (Ueno et al., 2007). This approach can be taken when a species is present in a treatment process but in insufficient numbers for adequate treatment. Selection of a strain from an alternative site may be the only option when a compound cannot be degraded by the species already present at location, however, success may be limited if the environmental conditions are not conducive to the survival of the inoculated strain (Thompson et al., 2005). 
Applications may include the use of a single strain or a combination of strains to produce a suitable consortium (Khehra et al., 2005; Qu et al., 2011). An individual strain may be selected for its ability to degrade a specific compound or due its role in a more complex degradation pathway. A number of strains may be used to replicate a natural community, enhance or replicate a catabolic pathway with numerous stages and/or degrade a number of target pollutants within the same wastewater (Van Limbergen, Top and Verstraete, 1998; Thompson et al., 2005). Increasingly, consortia are selected for bioaugmentation applications, with degradation processes frequently built upon the combined actions of numerous species, especially for the degradation of complex xenobiotic compounds (Stroo, Leeson and Herb Ward, 2013).

The success of a consortium was demonstrated by Khehra et al. (2005) for the treatment of recalcitrant dyes released from the textile processing industry. In laboratory investigations, both single strains and the consortium were supplemented with $20 \mathrm{mg} / \mathrm{L}$ of dye. Whilst the individual strains were able to decolourise 3 of the 6 dyes, to varying degrees, the consortium decolourised of all of the dyes. Further to this, the time required for the decolourisation was reduced from 24 hours to 8 hours. Due to the structural diversity of the dyes, the synergistic actions of the consortium proved to have a beneficial role. Similarly, the synergistic actions of a consortium previously developed by Chhatre et al. (1996) were recognised as important by Domde, Kapley and Purohit (2007) in the treatment of petroleum wastewater. In this application, a combination of isolates worked together to solubilise and then degrade various components of crude oil. One isolate was responsible for producing a biosurfactant followed by the emulsification of the crude oil which then made long chain aliphatics and aromatics available to the other two isolates for degradation. This combination of isolates resulted in an overall degradation rate of $65-70 \%$ and an increase in chemical oxygen demand (COD) removal from $15 \%$ without bioaugmentation to $52.2 \%$ with the consortium (Chhatre et al., 1996; Domde, Kapley and Purohit, 2007).

Genetic manipulation provides further opportunities for the degradation of compounds for which a pollutant-degrading natural strain does not exist (Stroo, Leeson and Herb Ward, 
117 2013). Microorganisms can be genetically engineered to over-express degradation genes or to 118 exhibit increased survivability (McClure, Fry and Weightman, 1991; Nüßlein et al., 1992;

119 Stroo, Leeson and Herb Ward, 2013). Such techniques enable the possibility of designing 120 microorganisms to assist with the treatment of pollutants which require numerous 121 degradation steps or those required to degrade xenobiotic compounds. Knowledge of the 122 degradation pathways involved for such compounds is limited and a naturally occurring 123 species capable of such degradation may not exist (Stroo, Leeson and Herb Ward, 2013). 124 Microorganisms which have been genetically modified have been investigated in 125 groundwater aquifer microcosms (Jain et al., 1987), lake waters (Awong, Bitton and 126 Chaudhryt, 1990) and ASP (McClure, Weightman and Fry, 1989; McClure, Fry and 127 Weightman, 1991). McClure, Weightman and Fry (1989) demonstrated that genetically 128 engineered bacteria were able to survive within a laboratory-scale ASP and did not encourage 129 protozoa reproduction despite large numbers of bacteria being inoculated. Additionally 130 Nüßlein et al. (1992) were able to confirm that microorganisms that were genetically engineered were not only capable of surviving in an ASP but were also able to maintain their genetic information and degrade the required pollutants. Such genetic adaptation may allow for the design of microorganisms which are able to assist in the degradation of pollutants 134 which require numerous degradation steps. Further to the genetic modification of 135 microorganisms, gene bioaugmentation, which involves the use of catabolic mobile genetic 136 elements (MGEs), has been highlighted in regard to its applicability to bioaugmentation 137 (Stroo, Leeson and Herb Ward, 2013). Mobile genetic elements consist of pieces of 138 deoxyribonucleic acid (DNA) or ribonucleic acid (RNA) which can be transferred from one organism to another (Stroo, Leeson and Herb Ward, 2013).

141 Despite the numerous possible ways in which genetic engineering may improve the future of 142 bioaugmentation, current research is heavily laboratory based and success in the field cannot 143 currently be fully assessed due to legislative restrictions resulting from concerns surrounding 144 the risks to both the environment and human health of the uncontrolled spread of 145 microorganisms which have been genetically engineered (Van Limbergen, Top and 146 Verstraete, 1998). Strategies such as the use of a 'suicide element' and immobilisation 147 techniques have been considered in order to reduce such risks (Liu, Huang and Wang, 2008; 
148 Stroo, Leeson and Herb Ward, 2013). Suicide techniques, for example, may be repressed by 149 an environmental signal such as from the pollutant to be degraded. When the signal no longer 150 exists the suicide element is activated. This technique has been shown to be successful in 151 preventing the spread of engineered cells (Torres, Garcia and Diaz, 2003). Legislation often 152 ignores the ways in which molecular genetics can be used for risk mitigation, and 153 consequently, future research will have to both inform and follow the regulations (Davison, 154 2005; Stroo, Leeson and Herb Ward, 2013).

156 Commercial inocula are now also widely available. Such products vary greatly in their makeup, cell density, advised dosing rates and the incorporation of other additives e.g. stabilisers and nutrients. Each of these factors need to be considered when selecting a suitable product

159 (Stroo, Leeson and Herb Ward, 2013). The use of commercial inocula may offer a short-term 160 solution to an immediate treatment issue; however, success rates may vary because such inocula are typically produced and tested under stable conditions. Such conditions do not reflect the real-life scenario relevant to many industrial wastewaters, in turn reducing the survivability of the inocula (Stephenson and Stephenson, 1992).

\section{Operational considerations}

167 The application of bioaugmentation is more likely to be successful in a treatment system with 168 well-characterised wastewater and operational parameters. This knowledge helps to identify 169 potential obstacles to the survival of the inoculated bacteria, including toxicity and nutrient 170 availability (Jianlong et al., 2002). Without a detailed knowledge of the system, the 171 likelihood of a successful integration of the inoculum is reduced. Activated sludge processes 172 can differ greatly in their configuration, although principally they consist of one or more 173 treatment cells containing biomass which may be aerobic, anoxic or anaerobic in nature. Such 174 treatment cells may operate under continuous flow conditions, in mixed systems or be 175 operated under a batch or plug-flow system. The introduction and maintenance method for 176 bioaugmentation applications should therefore be informed by the design of the treatment 
177 system. Treatment efficiencies and pollutant concentrations, on the other hand, will inform decisions relating to dosing rates (Stephenson and Stephenson, 1992; Park et al., 2008).

\subsection{Dosing technique}

182 Direct dosing involves the addition of the selected microorganisms straight into a treatment vessel. Such a technique represents the simplest method of bioaugmentation and can be advantageous in the sense that it can be applied as and when required. This can also be economically beneficial as it does not require plant modification and the associated operational costs. Problematic to this approach, however, is the reduced survival rates of the inoculated microorganisms due to a lack of acclimatisation to the environmental conditions of the host environment resulting, for example, from toxicity, $\mathrm{pH}$, carbon availability, predation and competition between the indigenous and inoculated bacteria (Chong, Pai and Chen, 1997;

190 Bouchez et al., 2000; Songzhe et al., 2009). The use of a side-stream reactor can help to overcome some of the aforementioned problems as it enables the acclimatisation of the inoculated microorganisms to the environmental conditions, thus increasing their survival rate in the treatment process (Parker and Wanner, 2007). The footprint of a side-stream is

194 typically approximately $10 \%$ that of the main reactor. As the side-stream can enable process 195 intensification, this can represent a much smaller investment cost than the cost associated with expanding a treatment works to cope with a higher capacity. Despite this, in some instances the additional land requirements may still be problematic (Salem et al., 2003). The use of encapsulation techniques can assist in the incorporation of inoculated bacteria into the existing flocs (Stormo and Crawford, 1992). Bouchez et al. (2009) mixed the inoculum with an alginate solution, forming bead structures which were employed in the reactor. The beads allowed the inoculated bacteria to remain in the system and protected them from the intense grazing that was experienced without such encapsulation. The beads were observed to break into fragments by day 8 , but such fragments were incorporated into flocs of the indigenous sludge, allowing their successful incorporation into the system. Another recent strategy that 
206 of aerobic granules of pure strains formed in a sequencing batch reactor (SBR) to the main treatment reactor (Shen et al, 2009; Liu et al, 2015).

\subsection{Dosing location}

211 The success of bioaugmentation has been shown to be influenced significantly by the location 212 at which the selected microorganisms are dosed. Dosing location should be selected based on 213 a careful consideration of the environmental conditions that the selected microorganisms 214 require in comparison to those they will face. Determination of the most suitable location 215 may be more critical in industrial wastewaters, which frequently contain single or multiple 216 pollutants known for their toxic effects. The impact of the identification of the correct 217 location was demonstrated by Jianlong et al. (2002) during the treatment of coke-making 218 wastewater. The wastewater, characterised by the presence of multiple toxic compounds, was treated through an ASP with an anaerobic, anoxic and aerobic reactor. Burkholdiera pickettii, a quinoline degrading species, was shown to have a beneficial role at any location; nevertheless, its positive impact was higher when Burkholdiera pickettii was added to the aerobic reactor. The provision of a suitable food source and the lower toxicity, as a result of the degradation of co-occurring compounds in previous treatment cells to smaller compounds, resulted in higher degradation efficiencies. Similar conclusions were drawn for the removal of 2-4-dichlorophenol in a laboratory-scale ASP. A mixed culture was developed through the enrichment of sludge taken from two wastewater treatment plants. The mixed culture was then added to a separate reactor with a carrier system of plastic lace strings (Quan, Shi, Liu, Wang, et al., 2004). Removal was higher, at 90.3\%, when the bioreactor was located after the aeration cell than when the bioreactor was situated before the aeration cell (86.2\% removal). It had been assumed that locating the bioreactor before the aeration cell would allow the removal of 2-4-dichlorophenol, which in turn would improve the removal efficiency of other pollutants as a result of the lowered toxicity of the wastewater. Despite this, the 2-4-dichlorophenol removal decreased when the bioreactor was placed before the aeration cell as a lack of easily degradable compounds resulted in a decrease in the removal of the targeted 2-4-dichlorophenol. When the bioreactor was placed after the aeration cell, the 
236 bioaugmented culture was able to specialise in the removal of 2-4-dichlorophenol, increasing 237 the treatment efficiency.

\subsection{Dosing size and regime}

241 Dosing characteristics and regimes vary considerably between the different applications of bioaugmentation. The first characteristic that requires consideration is the initial inoculum size, which should be sufficiently large enough to overcome initial predation pressures whilst not so large as to result in a disturbance to the ecosystem equilibrium. Ramadan, El-Tayeb and Alexander (1990) reported that p-nitrophenol containing wastewater required a high initial dose $\left(4.3 \times 10^{4}\right.$ cells per $\left.\mathrm{mL}\right)$ in order to overcome predation pressures. In contrast, Bouchez et al. (2000) reported a disturbance of the ecosystem balance resulting from increased pressures due to a large inocula dose Secondly, the use of maintenance doses may be necessary in order to maintain the population of the inoculated bacteria which may decrease over time as a result of routine sludge wastage or inherently low survival rates. The need for a maintenance dose varies from application to application. Boon et al. (2003) noted that bioaugmentation was not a permanent process when investigating the removal of 3chloroaniline whilst Martín-Hernández, Suárez-Ojeda and Carrera (2012) reported that maintenance doses were not necessary when the initial dose was high enough to overcome initial predation pressures.

\section{Bioaugmentation failures and associated improvement techniques}

259 Successful reports concerning bioaugmentation have also been associated with reports of 260 unsuccessful bioaugmentation attempts. Fundamental to the success of any application is the 261 ability of the inoculated bacteria to survive and prosper. Numerous factors have been cited 262 for the failure of bioaugmentation (Table 2) including the growth rate of the microorganism 263 being lower than the rate of washout (Boon et al., 2000), an insufficient inoculum size 264 (Ramadan, El-Tayeb and Alexander, 1990), an insufficient substrate (Goldstein, Mallory and 
265 Alexander, 1985; Bouchez et al., 2000; Tyagi, da Fonseca and de Carvalho, 2011; Martín-

266 Hernández, Suárez-Ojeda and Carrera, 2012), predation by protozoa (Goldstein, Mallory and

267 Alexander, 1985; Boon et al., 2000; Bouchez et al., 2000), competition between the

268 inoculated and indigenous bacteria (Stephenson and Stephenson, 1992; Bouchez et al., 2000;

269 More et al., 2010), the presence of other inhibiting substances (Goldstein, Mallory and

270 Alexander, 1985; Bouchez et al., 2000; Tyagi, da Fonseca and de Carvalho, 2011), the

271 availability of alternative substrates (Goldstein, Mallory and Alexander, 1985; Chitra et al.,

272 1995; Quan, Shi, Liu, Wang, et al., 2004; Mahin et al., 2011), the need for an acclimatisation

273 period (Stephenson and Stephenson, 1992) and extremes in environmental factors such as

274 temperature and $\mathrm{pH}$ (Tyagi, da Fonseca and de Carvalho, 2011). An understanding of the root

275 cause of the failure of the bioaugmentation process is important to ensure the advancement of

276 bioaugmentation applications.

277

278 Grazing was held responsible for the failure of $M$. aerodenitrificans becoming established in 279 an aerobic nitrifying sequencing batch reactor by Bouchez et al. (2000). The added bacteria 280 were associated with the liquid phase of the reactor and were not incorporated into bacterial 281 flocs. As a result of their suspended nature they were targeted by grazing protozoa, which 282 have grazing rates proportional to the fast rates of decline seen in the system. Ramadan, El283 Tayeb and Alexander (1990) also saw a decline in the inoculated bacterial abundance which 284 coincided with the multiplication of protozoa in the treatment of p-nitrophenol (PNP)containing wastewaters. Similarly, an overgrowth of protozoa as a result of bioaugmentation was reported by Songzhe et al. (2009) during the removal of ammonia from marine aquaculture wastewaters. Furthermore, a rapid decline of the denitrifier Pseudomonas stutzeri TR2 was again associated with probable predation during the treatment of piggery wastewater (Ikeda-Ohtsubo, Miyahara, Kim, et al., 2013). Songzhe et al. (2009) concluded that a form of protection, e.g. encapsulation from grazing, was necessary. An alternative approach investigated related to the ability of heat treatment to protect the inoculated bacteria

292 from predation (Ikeda-Ohtsubo, Miyahara, Yamada, et al., 2013) and results showed that

293 adapting the reactor conditions overcame the predation problems. When the temperature of 294 the treatment reactor was reduced to $35^{\circ} \mathrm{C}$ the predators were able to proliferate and during 295 this period, there was a rapid tenfold increase in their associated genes. When the temperature 
was increased to $40-44^{\circ} \mathrm{C}$ there was no increase in the number of genes representing predators and therefore Pseudomonas stutzeri TR2 was protected from predation.

299 Contrary to reports concerning the negative effects of grazing on bioaugmentation, Yu, Peng 300 and Ren (2011) demonstrated that grazing did not have a significant impact on nitrogen removal. Nitrification efficiencies were monitored in a bioaugmentation system in which all protozoa were inhibited and compared to one in which protozoa were not inhibited. Although initially protozoa numbers increased rapidly in the non-inhibited reactor, their numbers then declined gradually over the duration of the study and complete nitrification was ultimately possible in both reactors. The increased time requirement, from 71 days with protozoa inhibition to 76 days without protozoa inhibition, was not considered to be significant.

308 Nutrient limitation is a particularly important factor in the treatment of industrial wastewaters 309 which frequently lack the essential nutrients required for microbial development (Burgess, 310 Quarmby and Stephenson, 1999). Nutrient limitations have been held responsible for failed 311 bioaugmentation attempts due to the competition between the indigenous and inoculated 312 bacteria. Ramadan, El-Tayeb and Alexander (1990) demonstrated that the supplementation of 313 nutrients could increase the likelihood of a successful bioaugmentation outcome as the 314 addition of nitrogen and phosphate allowed for low densities of inoculum to remove p315 nitrophenol (PNP), potentially increasing the inoculum growth rates and resistance to higher 316 protozoa numbers. Such nutrient addition is referred to as biostimulation. Biostimulation, 317 however, can also include the addition of other stimulants such as surfactants. Nikolopoulou, 318 Pasadakis and Kalogerakis (2013) demonstrated that the presence of a biosurfactant could 319 increase degradation rates in oil-contaminated sites by enhancing the solubility of the 320 hydrocarbons. Under such treatment systems it is important, however, to have adequate controls in place in order to be able to assess to what degree the improvement is a result of the biostimulation rather than a result of the bioaugmentation itself. Due to its complementary action, biostimulation has therefore become a technique that is frequently reported for use alongside bioaugmentation (Wenderoth et al., 2003; Olaniran, Pillay and Pilay, 2006; Tyagi, 
325 da Fonseca and de Carvalho, 2011; Nikolopoulou, Pasadakis and Kalogerakis, 2013; Shoji et al., 2014; Sun et al., 2014).

328 Industrial wastewaters are frequently characterised by changing load rates which result in fluctuating concentrations of the target compounds. Some failures of the bioaugmentation process have been linked to long periods of starvation in the target pollutant. One means with which to tackle this problem is to select an initial dose which is high enough to allow a proportion of the bacteria to persist in the treatment system until the load rate increases again.

333 This approach was investigated by Martín-Hernández, Suárez-Ojeda and Carrera (2012) during the treatment of $\mathrm{p}$-nitrophenol in a laboratory-scale sequencing batch reactor. Using a dose rates of $2 \%$ and $5 \%$ respectively, it was found that the higher initial dose rate allowed the inoculated bacteria to survive the 20 day period of starvation and maintain subsequent treatment. Importantly, the dose rate of 5\% was still practical in terms of its application to full-scale treatment works. In contrast Duque et al. (2011) found that periods of substrate inhibition did not cause failure during the treatment of 2-fluorophenol in a rotating biological contactor.

342 For some bioaugmentation applications failure lies in the inadequate adaptation of the inoculum to the host environment. Chong, Pai and Chen (1997) reported that a mixed culture,

344 designed to treat petroleum wastewater, was unable to proliferate in the system, yielding no benefit to the water treatment under $\mathrm{pH}$ shock conditions and complete failure under continuous high $\mathrm{pH}$ conditions. The failure was linked to biomass washout as a result of growth retardation or death of the inoculated population. Biomass washout, as a result of poor reactor conditions, including an inadequate carrier system and violent air bubbling, was also reported by Park et al. (2008) in the treatment of cyanide wastewater. Additionally, Songzhe et al. (2009) reported that inoculated bacteria were unable to form an adequate biofilm due to interaction with other indigenous bacteria resulting in biomass washout and the failure of bioaugmentation. The likelihood of inadequate adaptation is increased with industrial wastewaters and this highlights the requirement for understanding the treatment conditions and adaptation techniques. 


Problem
Predation (Overgrowth of protozoa)
(Goldstein, Mallory and Alexander, 1985;
Ramadan, El-Tayeb and Alexander, 1990;
Songzhe et al., 2009; Martín-Hernández, Suárez-
Ojeda and Carrera, 2012)

Competition for nutrients between indigenous and inoculated bacteria

(Ramadan, El-Tayeb and Alexander, 1990; Yu et al., 2005; Martín-Hernández, Suárez-Ojeda and Carrera, 2012)

\section{Technique to overcome problem}

High initial doses (Ramadan, El-Tayeb and Alexander, 1990)

Protection from grazing (Songzhe et al., 2009)

Heat treatment (Ikeda-Ohtsubo, Miyahara, Yamada, et al., 2013)

Supplementation of nutrients (biostimulation) (Ramadan, El-Tayeb and Alexander, 1990)
Insufficient inoculations

(Ramadan, El-Tayeb and Alexander, 1990)

Poor biofilm formation

(Park et al., 2008; Songzhe et al., 2009)

Wash-out

(Chong, Pai and Chen, 1997; Park et al., 2008)

Decline of inoculated bacteria due to toxins

Repeated inoculations (Boon et al., 2003)

Continual inoculations (Abeysinghe et al., 2002)

Immobilisation/encapsulation (Stormo and Crawford, 1992; Quan, Shi, Liu, Lv, et al., 2004)

High initial doses (Ramadan, El-Tayeb and Alexander, 1990)

Immobilisation/encapsulation (Stormo and Crawford, 1992; Quan, Shi, Liu, Lv, et al., 2004)

Protection from adverse environmental conditions (Songzhe et al., 2009)

Allow acclimatisation period (Stephenson and Stephenson, 1992)

Use autochthonous bioaugmentation (Ueno et al., 2007)

Alternative substrates available

(Goldstein, Mallory and Alexander, 1985; Chitra

Detailed understanding of ecological background (Songzhe et al., 2009)

et al., 1995; Quan, Shi, Liu, Lv, et al., 2004;

Mahin et al., 2011)

Large inoculations disturbing balance of ecosystem

Careful consideration of dose rate

(Bouchez et al., 2000)

Periods of starvation

(Martín-Hernández, Suárez-Ojeda and Carrera, 2012)
Higher dose rate to allow survival in the system for longer time periods (Martín-Hernández, SuárezOjeda and Carrera, 2012) 


\section{Directive}

360 A wide variety of wastewaters are regulated under the IED, all of which could potentially 361 benefit from the application of bioaugmentation. An improved understanding of the 362 capabilities of bioaugmentation could therefore offer widespread opportunities for industrial 363 wastewater treatment. Industrial wastewaters can encompass a wide variety of pollutant 364 compounds, although typically some commonalities exist between the different wastewaters.

365 Nitrogen compounds are common to many types of wastewater, particularly those from the milk and food industries as well as coke processing activities. The levels of ammonia in cokemaking wastewater can vary from $123 \mathrm{mg} / \mathrm{L}$ up to 4,500 mg/L (Ganczarczyk, 1983; Gould, 1986). Ammonia concentrations vary between sites due to variations in the operational conditions and also temporally at a single site due to variations in production levels (Marañón et al., 2008). High concentrations of ammonia are also characteristic of dairy wastewaters. As with coke-making wastewaters, they are subject to both spatial and temporal variations due to difference in the products produced and the treatment methods in place. Furthermore, these wastewaters are often produced intermittently (Vidal et al., 2000).

Nitrogen is a key target pollutant as it can cause the eutrophication of receiving waters. Nitrifying bacteria grow more slowly than the general heterotrophic community and are less resistant to toxicity. Consequently, nitrifying bacteria may be outcompeted. Supplementation through bioaugmentation may therefore be beneficial to treatment systems characterised by a high nitrogen loading. As the removal of nitrogen occurs in a two-step process involving the oxidation of ammonia to nitrite and the subsequent oxidation of nitrite to nitrate, nitrifying treatment processes require process stability in order to allow the two steps to remain synchronised and to prevent accumulation of the more toxic nitrogen species nitrite. Abeysinghe et al. (2002) investigated the ability of bioaugmentation to support the nitrification process when operating under stress conditions. At a solids retention time of two days, the treatment system operated near washout conditions, but the addition of 45 and 67.5 $\mathrm{mg} / \mathrm{L}$ of ammonia oxidisers, allowed effluent ammonia concentrations to be reduced from 4.5 $\mathrm{mg} / \mathrm{L}$ to $<1 \mathrm{mg} / \mathrm{L}$. The application of bioaugmentation can therefore be an effective and 
convenient tool to support industrial treatment systems which frequently operate under stress conditions.

391 Obbard and Shan (2001) also reported the use of bioaugmentation to support the treatment of prawn aquaculture ponds which are characterised by high nitrogen loading rates but which experience high levels of nitrifier washout as a result of the regular exchange of pond water exchange employed to prevent the build-up of toxins in such ponds. Inert media have been reported to enhance treatment by increasing bacterial populations through biofilm formation (Stephenson et al., 2013). This technology has been selected in order to tackle the problem of washout, with indigenous nitrifiers immobilised onto porous clay pellets, allowing the total ammonical nitrogen to be reduced from $3 \mathrm{mg} / \mathrm{L}$ to $0.5 \mathrm{mg} / \mathrm{L}$, the latter being below the required concentration necessary for optimum prawn growth $(1.33-1.53 \mathrm{mg} / \mathrm{L})$ (Table 3).

400 The treatment of high nitrogen loads through bioaugmentation was reported by Onyia et al.

401 (2001) for palm oil wastewater (Table 3). Palm oil wastewaters are characterised by organic 402 nitrogen loads of $180-1,820 \mathrm{mg} / \mathrm{L}$ and the treatment of this type of wastewater is time 403 intensive, with more than 11 days required in order to achieve 50\% nitrification. However, the addition of $15 \mathrm{mg} / \mathrm{L}$ of a mixed nitrifying culture increased this efficiency to $100 \%$ within seven days.

406

407 Carrier materials have also been employed to support bioaugmentation. In the treatment of 408 petrochemical wastewater, Ma et al. (2009) used a carrier system of polyurethane foam to 409 encourage the inoculated bacteria to form a biofilm (Table 3). The resulting biofilm 410 prevented the washout of the inoculated bacteria as well as the gradual decrease in their 411 numbers as a result of predation. Additionally, the inoculated bacteria were provided with 412 organic substrates and inorganic trace elements to support their growth. Consequently, the 413 bioaugmented reactor showed better performance with decreased start-up times (20 days 414 compared to 30 days without bioaugmentation), a higher resistance to shock loads of COD, 415 higher treatment efficiencies of refractory organic compounds (reduced to 21 compared to 46 416 without bioaugmentation) and a reduction of effluent ammonia concentrations (4.1 $\mathrm{mg} / \mathrm{L}$ 417 compared to $12.4 \mathrm{mg} / \mathrm{L})$. 
418 Table 3: Examples of bioaugmentation applied to compounds present in industrial

419 wastewaters.

\begin{tabular}{|c|c|c|c|}
\hline Compound & Scale & Application & Conclusions \\
\hline
\end{tabular}

\section{Nitrogen}

(Onyia et al., Laboratory Palm oil effluent 2001)

(Obbard and

Shan, 2001)

(Ma et al., Full-scale 2009)

(Fang et al., Laboratory 2013)

(Duque et al., Laboratory 2011)

(Martín- Laboratory Hernández, Suárez-Ojeda and Carrera, 2012)

(Straube et al., Laboratory 2003) and pilot-
Synthetic alkaline wastewaters

Coal gasification wastewater

2-fluorophenol wastewaters

p-nitrophenol (PNP) wastewaters

PAH contaminated soil
$15 \mathrm{mg} / \mathrm{L}$ of mixed cultures led to $100 \%$ increase in nitrification.

Reduced HRTs led to $20 \%$ reduction in land requirement.

Immobilised bacteria allowed total ammonical nitrogen reduced from $3 \mathrm{mg} / \mathrm{L}$ to $0.5 \mathrm{mg} / \mathrm{L}$ allowing ponds to remain at optimal conditions.

Immobilisation prevented washout of nitrifiers.

National discharge limits met in 20 days compared to 30 days.

Effluent ammonia concentrations fell from $12.4 \mathrm{mg} / \mathrm{L}$ to $4.1 \mathrm{mg} / \mathrm{L}$.

Addition of Pseudomonas sp. JY-2 allowed improved start-up times $(90 \%$ removal compared to $65 \%$ after 1.5 days) and increase long-term treatment efficiency $\quad(90 \%$ compared to $80 \%$ ).

Bioaugmentation increased removal efficiencies from $66 \%$ to $80 \%$ despite high variation in levels of phenol (500-3000 $\mathrm{mg} / \mathrm{L})$.

2-fluorophenol degrading species FP1 allowed treatment of waters subjected to shock loads of up to $50 \mathrm{mg} / \mathrm{L}$ of 2fluorphenol.

Bioaugmentation allowed immediate removal of shock loads of PNP. Without bioaugmentation PNP removal took 4 days to reach $100 \%$ and then failed after 8 days.

Bio-surfactant producer Pseudomonas aeruginosa strain 64 increased $\mathrm{PAH}$ 
scale

(Sun et al., $\quad$ Pilot 2014) degradation from $23 \%$ to $34 \%$. Bioaugmentation and biostimulation increased degradation to $87 \%$. Biostimulation alone increased degradation to $86 \%$.

Former coke works contaminated soil
Total PAH levels fell by $24 \%$ in the control, $35.9 \%$ with bioaugmentation, and 59\% with biostimulation.

Bioaugmentation was responsible for the increased removal of heavy molecular weight molecules.

421 Bioaugmentation has also been used for the treatment of aromatic compounds including phenols and polycyclic aromatic hydrocarbons (PAHs) which are present in a wide variety of industrial wastewaters, including those from agrochemical, pharmaceutical, petrochemical, coal gasification, coke processing, insecticide and hydrocarbon wastewaters among others (Table 3). Aromatic compounds are regulated under the IED and are also listed as Priority Substances within the European Union (European Union, 2013).

Coal gasification wastewater is subject to a high variability of phenol concentration, from $500-3,000 \mathrm{mg} / \mathrm{L}$ as a result of fluctuations in the pre-treatment performance. Such variability can be problematic in regard to biological treatment due to the changing substrate levels and the subsequent decline in bacterial numbers during periods of limited food supply. However, system stability is of increasing importance as emission limits continue to be lowered. The addition of phenol-degrading bacteria by Fang et al. (2013) (Table 3) allowed phenol treatment efficiencies to increase from 66 to $80 \%$ and further increased the resistance to fluctuating loads. Ammonia removal also improved (5 to 25\%), although fluctuating ammonia load rates required a higher recovery time. Resistance to shock loading of phenolic compounds was also seen to improve due to bioaugmentation in the work of Duque et al.

438 (2011) for the removal of 2-fluorphenol. Interestingly, Duque et al. (2011) promoted biofilm 439 formation in a rotating biological contactor (RBC) through batch application of the inoculum.

440 This technique provided a means via which the system was able to stabilise and consequently 441 long-term maintenance was not required. This allowed for improved resistance to shock loads 442 and increased resistance to periods of starvation (Table 3). Although improved resistance to 443 shock loads of p-nitrophenol was also observed by Martín-Hernández, Suárez-Ojeda and 
444 Carrera (2012), resistance to starvation periods was determined as a function of the size of the initial inoculum dose (Table 2).

447 The stable removal of both pyridine and quinoline from coke-making wastewater was 448 observed after the inoculation of a laboratory-scale sequencing batch reactor filled with 449 modified zeolite (Zhang et al., 2014b). Removal of both compounds was maintained at 100\% 450 whereas removal efficiencies could vary from 0 to $93 \%$ without bioaugmentation. This was 451 attributed to an improved bacterial diversity, which increased the resistance to shock 452 loadings. The interaction of species in a mixed culture of four species (Paracoccus sp. BW001, Shinella zoogloeoides BC026 and Pseudomonas sp. BC001) was believed to be responsible for the success of bioaugmentation for the removal of pyridine and quinoline in coke-making wastewaters (Bai et al., 2010).

Polycyclic aromatic hydrocarbons (PAHs) can be found in oil and gas wastewaters as well as coke-making wastewaters and are typically difficult to treat as they accumulate in the suspended solids of ASP, reducing their bioavailability to microbial degradation (Douben, 2003). Examples of bioaugmentation to enhance removal of PAHs typically focus on the treatment of contaminated soils and groundwater (Vogel, 1996; Straube et al., 2003; Yu et al., 2005; Jacques et al., 2008; Silva et al., 2009; Teng et al., 2010). Useful knowledge may be gained from these applications, however, since PAHs are mainly associated with the suspended solids in ASPs.

466 Straube et al. (2003) and Sun et al. (2014) both considered the role of bioaugmentation and 467 biostimulation for the removal of PAHs from soil (Table 3). Biostimulation was applied in 468 order to overcome environmental limitations. Straube et al. (2003) demonstrated the ability of 469 the bio-surfactant-producer Pseudomonas aeraginosa strain 64 to stimulate the 470 autochthonous PAH degraders in soil samples. After 11 months, bioaugmentation led to an 471 increase in PAH degradation from 23 to $34 \%$. Biostimulation in combination with 472 bioaugmentation however led to an increase in the PAH degradation to $87 \%$. At pilot scale, 
473 after 16 months, PAH removal increased from $12 \%$ in the control to $87 \%$ with 474 bioaugmentation and biostimulation, although, $86 \%$ removal could in fact be achieved with 475 biostimulation alone. Sun et al. (2014) found comparable results to Straube et al. (2003) 476 when researching the impact of bioaugmentation and biostimulation on former coke works. 477 Over a 3 month period the total PAH levels fell by $24 \%$ in the control, $35.9 \%$ with 478 bioaugmentation and by $59 \%$ with biostimulation. The combination of bioaugmentation and 479 biostimulation only brought about small improvements in comparison to biostimulation 480 alone. The removal of heavy molecular weight PAHs, however, was noticeably higher with 481 bioaugmentation than with biostimulation alone. This is significant due to the increased resistance of heavy molecular weight PAHs to degradation.

483

\section{Discussion and Conclusions}

485

486

The consistent and stable removal of priority pollutants from industrial wastewater is essential. Whilst close system monitoring and process control are important factors in achieving stable operation and meeting emission limits, operational regimes also need to be economically viable. Even with optimal process control, the inherent variability of industrial wastewaters can still result in emission variability. Compliance with increasingly stringent emission limits therefore requires the application of additional techniques to both meet the required limits and respond to transient treatment issues. Whilst achieving effluents of increasingly high quality is important in the long term, it is equally important that techniques are developed to re-establish treatment promptly after transient events have occurred. Bioaugmentation should be considered as one such technique.

497 Compliance with nitrogen effluent standards affects a wide variety of industries including 498 palm oil effluent, aquaculture wastewaters, coke making wastewaters and petrochemical 499 wastewaters. Nitrification is well known for its process instability due to the requirement for 500 the close linking of the bacterial species responsible for different parts of the removal process 501 (Philips, Laanbroek and Verstraete, 2002). Low growth rates of nitrifying bacteria and uncoupling of the nitrification chain can be problematic in any treatment, but those of an 
503

504

505

506

507

508

509

510

511

512

513

514

515

516

517

518

519

520

521

522

523

524

525

526

527

528

529

530

531

532

industrial nature are much more susceptible to disruption as a result of their characteristic variations in loading and the frequent presence of toxic compounds. Bioaugmentation has been shown to offer the potential to stabilise nitrification and in particular to deal with transient treatment problems. Abeysinghe et al. (2002) demonstrated the ability of bioaugmentation to improve ammonia removal during stress conditions. Similarly, Ma et al. (2009) demonstrated the improved capability of a bioaugmented ASP-treating petrochemical wastewater to deal with shock loadings of COD. Recovery from shock loading was also $50 \%$ faster. Compliance can also be problematic for priority pollutants which are persistent and toxic, as the biomass not only requires acclimation but it can still be negatively impacted by a sudden shock load of the toxic compound. As with nitrogen, bioaugmentation has been demonstrated to have some success in the treatment of such compounds. Qu et al. (2011) observed improved long-term stability of treatment systems for treating aromatic compounds. The addition of Pseudomonas sp. JY-2 led to $90 \%$ removal efficiencies compared to $80 \%$ without bioaugmentation, with the additional benefit of decreased start-up times. Both Duque et al. (2011) and Fang et al. (2013) also observed an improved resistance of treatment systems to fluctuating phenol levels with the application of bioaugmentation.

Despite the benefits which have already been reported, caution must be applied to the findings of the numerous reported investigations. For instance, under the stress conditions reported by Abeysinghe et al. (2002), daily dosing was required to maintain sufficient levels of the microorganisms. Bioaugmentation was therefore capable of dealing with transient issues, but would be uneconomic for the long-term maintenance of an unstable treatment system. Similarly, although Ma et al. (2009) demonstrated improved nitrogen removal efficiencies, bioaugmentation was conducted in a system with immobilisation and then compared against a conventional reactor. The reduced washout, which was the main benefit of the former system, could therefore potentially have been achieved through the use of carrier media alone, simply supporting biofilm formation. It is important therefore that the purpose of bioaugmentation is clearly defined before success is determined e.g. whether a short-term solution technique or long-term benefits are desired. 
533 A significant benefit of bioaugmentation is its ability to treat on demand. Direct dosing can 534 provide an immediate solution to a wide array of failing treatment systems. Where space is an issue and treatment systems are already operating at their maximum capabilities,

536 bioaugmentation may be the only way by which to maintain effluent compliance without 537 resorting to the halting of upstream operations. Direct dosing may make use of commercial 538 products, but these have been associated with a tendency to fail to produce the reported 539 benefits of the product and/or require higher dosing rates than suggested by the manufacturer 540 (Stephenson and Stephenson, 1992). These products may be able to offer a short-term solution to an immediate problem, but because of the problems associated with inadequate adaption of the microorganisms to the environment and the high dosing levels required, they may not be able to meet the requirements for long-term use. As the economic costs associated with treatment processes become more pertinent, the use of 'one-off' dosing may become less viable. The use of side-stream technologies is becoming increasingly common due to their advantages in terms of bacterial adaptation and use in long-term bioaugmentation applications (Krhutková et al., 2006; Smith et al., 2008; Yu, Peng and Pan, 2012).

549 Despite some positive reports of the impact of bioaugmentation on process performance, 550 there are still substantial areas that require further research. Firstly, one of the most important aspects requiring research involves the development of an increased understanding of degradation pathways, in the absence of which the possibility of finding a suitable species to inoculate a given compound is reduced. The area of strain development has previously been highlighted for its importance (Thompson et al., 2005). It is not only important to consider which strain(s) may be required, but also the requirements of that the strain to operate successfully. Under some circumstances the use of biostimulation may be necessary in order to provide nutrients, or other critical components such as biosurfactants, for the decontamination process to be successful. The synergistic action of a consortium was highlighted by Khehra et al. (2005) whilst the importance of the combined action of a 560 biosurfactant and a pre-adapted consortium was reported by Nikolopoulou et al. (2013). More research in this field may support the degradation of wastewaters containing polycyclic aromatic hydrocarbons, where complex compounds of different molecular weights are present simultaneously. Developments in genetics may also assist in the development of 
564 strains suitable to target xenobiotic compounds for which removal is currently limited; however, concerns around the release of genetically modified bacteria have significantly impacted progress in this area (Davison, 2005). Van Der Gast et al. (2003) also reported that treatment performance was more reproducible for a constructed consortium than an undefined community.

The success of bioaugmentation is increasingly being linked to the effective incorporation of the inoculated strain into the host environment, the success of which is influenced by issues ranging from strain selection and the introduction strategy through to the ability of the strain to survive within the environment to which it is introduced (Herrero and Stuckey, 2014;

574 Thompson et al., 2005). The importance of having a detailed knowledge of the treatment system has been emphasised through numerous applications (Goldstein, Mallory and Alexander, 1985; Bouchez et al., 2000; Songzhe et al., 2009; Martín-Hernández, SuárezOjeda and Carrera, 2012). An understanding of the conditions in a treatment process offers a way in which to prevent an inoculum being negatively influenced by environmental factors such as $\mathrm{pH}$ and temperature, as well as exposure to toxic compounds, allowing for the selection of a dosing strategy or location for introduction of the strain to minimise its exposure to negative conditions. Such detailed knowledge can also help inform possible solutions to any problems that may arise. Industries such as dairy processing, where each site encompasses different process operations, would particularly benefit from this approach. As bioaugmentation methodologies can vary greatly, the technique allows for the individuality of different treatment processes to be recognised and catered for.

587 Appropriate dosing rates also lack sufficient research. Although many references have been 588 made to over-dosing and/or under-dosing, huge variations can be seen in dose rates that have been successful between applications which appear to be very similar. In the treatment of pyridine and quinoline in laboratory-scale SBRs, both treating wastewater from the same site and achieving a 99\% removal rate, Bai et al. (2010) reported a dose rate of 0.007-0.0200 g/L

592 in comparison to a dose of $0.223 \mathrm{~g} / \mathrm{L}$ for Zhang et al. (2014b). Of the three species used in 593 each study, two of the species applied were the same in both applications. Whether the 
594 relatively large difference in dose rate can be accounted for by the third species is unknown.

595 Research is also contradictory in the need for repeated inoculations through maintenance dose 596 rates. Both Boon et al. (2003) and Abeysinghe et al. (2002) reported the need for repeated 597 inoculations via maintenance doses whilst Martín-Hernández, Suárez-Ojeda and Carrera 598 (2012) reported that this was unnecessary if the initial dose rate was sufficiently high to 599 overcome initial survival pressures. High dosing rates have equally been criticised as they 600 have been linked to disturbances in the balance of an ecosystem (Bouchez et al., 2000). For 601 this reason, it is important that investigations take place which consider a variety of different dosing regimens for identical wastewater treatment facilities.

603 The complexity of industrial wastewaters increases the challenge of identifying the most 604 effective techniques, as many interacting processes can take place simultaneously. Despite 605 this, industries should take the opportunity to learn from previous bioaugmentation successes 606 and failures in order to gain from the benefits that may be obtained from bioaugmentation. 607 Research has already increased our understanding of the complex interactions between the 608 introduced microorganisms and the host environment, leading to improved application 609 success. Many of the problems that have arisen in the field of bioaugmentation have been 610 overcome through process development (Error! Reference source not found. 2).

612 For the field of bioaugmentation to move forward, it is now essential for key gaps in the 613 research to be addressed. Overall, when considering whether bioaugmentation is successful, 614 the aim of the bioaugmentation process must first be considered i.e. short-term solution to a 615 treatment issue or the long-term improvement of a system. Current research has been limited 616 by the focus on laboratory-scale investigations, synthetic wastewaters and the failure to have 617 adequate controls in place. Understanding in the field would be enhanced significantly by 618 operating parallel studies with control and test process streams. Full-scale investigations have 619 been limited in extent and such investigations have also lacked controls (Parker and Wanner, 620 2007). 
623 This work was supported by Tata Steel UK and the Natural Environment Research Council 624 [grant number NE/K007424/1].

625

\section{References}

627 Abeysinghe, D. H., De Silva, D. G. V., Stahl, D. a and Rittmann, B. E. (2002) 'The 628 effectiveness of bioaugmentation in nitrifying systems stressed by a washout condition and 629 cold temperature.', Water environment research: a research publication of the Water 630 Environment Federation, 74(2), pp. 187-99.

631 Awong, J., Bitton, G. and Chaudhryt, G. R. (1990) 'Microcosm for Assessing Survival of 632 Genetically Engineered Microorganisms in Aquatic Environments', Applied and 633 environmental microbiology, 56(4), pp. 977-83.

634 Bai, Y., Sun, Q., Zhao, C., Wen, D. and Tang, X. (2010) 'Bioaugmentation treatment for 635 coking wastewater containing pyridine and quinoline in a sequencing batch reactor', Applied 636 Microbiology and Biotechnology, 87(5), pp. 1943-1951. doi: 10.1007/s00253-010-2670-8.

637 Bartrolí, A., Carrera, J. and Pérez, J. (2011) 'Bioaugmentation as a tool for improving the 638 start-up and stability of a pilot-scale partial nitrification biofilm airlift reactor.', Bioresource 639 technology, 102(6), pp. 4370-5. doi: 10.1016/j.biortech.2010.12.084.

640 Bitton, G. (2011) Wastewater Microbiology. 4th edn. Wiley-Blackwell.

641 Boon, N., Goris, J., Vos, P. De, Verstraete, W. and Top, E. M. (2000) 'Bioaugmentation of 642 Activated Sludge by an Indigenous 3-Chloroaniline-Degrading Comamonas testosteroni 643 Strain , I2 gfp', Applied and Environmental Microbiology, 66(7), pp. 2906-13. doi: 644 10.1128/AEM.66.7.2906-2913.2000.Updated.

645 Boon, N., Top, E. M., Verstraete, W., Steven, D. and Siciliano, S. D. (2003) 646 'Bioaugmentation as a Tool To Protect the Structure and Function of an Activated-Sludge 647 Microbial Community against a 3-Chloroaniline Shock Load.', Applied and environmental 648 microbiology, 69(3), pp. 1511-19. doi: 10.1128/AEM.69.3.1511. 
649 Bouchez, T., Patureau, D., Dabert, P., Juretschko, S., Doré, J., Delgenès, P., Moletta, R. and 650 Wagner, M. (2000) 'Ecological study of a bioaugmentation failure.', Environmental 651 microbiology, 2(2), pp. 179-90.

652 Bouchez, T., Patureau, D., Delgenès, J. P. and Moletta, R. (2009) 'Successful bacterial 653 incorporation into activated sludge flocs using alginate', Bioresource Technology. Elsevier 654 Ltd, 100(2), pp. 1031-1032. doi: 10.1016/j.biortech.2008.07.028.

655 Burgess, J. E., Quarmby, J. and Stephenson, T. (1999) 'Role of micronutrients in activated 656 sludge-based biotreatment of industrial effluents', Biotechnology Advances, 17, pp. 49-70.

657 Chhatre, S., Purohit, H., Shanker, R. and Khanna, P. (1996) 'Bacterial consortia for crude oil 658 spill remediation', Water Science \& Technology, 34(10), pp. 187-193.

659 Chitra, S., Sekaran, G., Padmavathi, S. and Chandrakasan, G. (1995) 'Removal of phenolic 660 compounds from wastewater using mutant strain of Pseudomonas pictorum', Journal of 661 general and applied microbiology, 41(3), pp. 229-37.

662 Chong, N.-M., Pai, S.-L. and Chen, C.-H. (1997) 'Bioaugmentation of an activated sludge 663 receiving $\mathrm{pH}$ shock loadings', Bioresource Technology, 59(2-3), pp. 235-240. doi: 664 10.1016/S0960-8524(96)00138-1.

665 Davison, J. (2005) 'Risk mitigation of genetically modified bacteria and plants designed for 666 bioremediation', Journal of Industrial Microbiology and Biotechnology, 32(11-12), pp. 639667 650. doi: 10.1007/s10295-005-0242-1.

668 Domde, P., Kapley, A. and Purohit, H. J. (2007) 'Impact of Bioaugmentation with a 669 Consortium of Bacteria on the Remediation of Wastewater-Containing Hydrocarbons.', 670 Environmental science and pollution research international, 14(1), pp. 7-11.

671 Douben, P. E. T. (2003) PAHs: An Ecotoxicological Perspective. England: John Wiley \& 672 Sons.

673 Duque, A. F., Bessa, V. S., Carvalho, M. F. and Castro, P. M. L. (2011) 'Bioaugmentation of 674 a rotating biological contactor for degradation of 2-fluorophenol.', Bioresource technology. 675 Elsevier Ltd, 102(19), pp. 9300-3. doi: 10.1016/j.biortech.2011.07.003. 
676 European Commission (2003) 'Integrated Pollution Prevention and Control Reference 677 Document on Best Available Techniques in Common Waste Water and Waste Gas Treatment 678 / Management Systems in the Chemical Sector'. Available at: 679 http://eippcb.jrc.ec.europa.eu/reference/BREF/cww_bref_0203.pdf.

680 European Commission (2006) Integrated Pollution Prevention and Control Reference 681 Document on Best Available Techniques in the Food, Drink and Milk Industries. Available 682 at: http://eippcb.jrc.ec.europa.eu/reference/BREF/fdm_bref_0806.pdf.

683 European Commission (2011) Reference Documents: Best Available Techniques Reference 684 Document (BREFs). Available at: http://eippcb.jrc.ec.europa.eu/reference/.

685 European Commission (2012) (BAT) conclusions under Directive 2010/75/EU of the 686 European Parliament and of the Council on industrial emissions for the manufacture of 687 glass.

688 European Commission (2013a) Best Available Techniques (BAT) Reference Document for 689 Iron and Steel Production, Industrial Emissions Directive 2010/75/EU. doi: 10.2791/97469.

690 European Commission (2013b) 'Best Available Techniques (BAT) Reference Document for 691 the Manufacture of Glass'.

692 European Commission (2014) Best available technique conclusions, under Directive 693 2010/75/EU of the European Parliament and of the Council on industrial emissions, for the 694 refining of mineral oil and gas. Available at: http://eur-lex.europa.eu/legal695 content/EN/TXT/?uri=OJ:JOL_2014_307_R_0009.

696 European Commission (2015a) Best Available Techniques (BAT) Reference Document for the 697 Refining of Mineral Oil and Gas.

698 European Commission (2015b) The Industrial Emissions Directive. Available at: 699 http://ec.europa.eu/environment/industry/stationary/ied/legislation.htm (Accessed: 11 $700 \quad$ November 2015).

701 European Union (2013) Annex 1 List of priority substances in the field of water policy. 702 Available at: 
703

704

705

706

707

708

709

710

711

712

713

714

715

716

717

718

719

720

721

722

723

724

725

726

727

728

729

730

http://www.europarl.europa.eu/sides/getDoc.do?type=TA\&language=EN\&reference=P7-TA2013-298 (Accessed: 3 December 2013).

Fang, F., Han, H., Zhao, Q., Xu, C. and Zhang, L. (2013) 'Bioaugmentation of biological contact oxidation reactor (BCOR) with phenol-degrading bacteria for coal gasification wastewater (CGW) treatment.', Bioresource Technology. Elsevier Ltd, 150, pp. 314-20. doi: 10.1016/j.biortech.2013.09.119.

Ganczarczyk, J. J. (1983) 'Second-Stage Activated Sludge Treatment of Coke-Plant Effluents', Water Research, 13, pp. 337-342.

Van Der Gast, C. J., Whiteley, A. S., Starkey, M., Knowles, C. J. and Thompson, I. P. (2003) 'Bioaugmentation strategies for remediating mixed chemical effluents', Biotechnology Progress, 19(4), pp. 1156-1161. doi: 10.1021/bp020131z.

Gerrard, A. M. and Stephenson, T. (1990) 'Some economic targets for inoculum enhanced activated sludge processes', Process Safety and Environmental Protection, 68b, pp. 269-272.

Goldstein, R. M., Mallory, L. M. and Alexander, M. (1985) 'Reasons for possible failure of inoculation to enhance biodegradation', Applied and environmental microbiology, 50(4), pp. 977-83.

Gould, F. J. (1986) Biological effluent treatment using pure oxygen, The Coke Oven Managers' Yearbook.

Guo, J., Ma, F., Chang, C., Cui, D., Wang, L., Yang, J. and Wang, L. (2009) 'Start-up of a two-stage bioaugmented anoxic-oxic (A/O) biofilm process treating petrochemical wastewater under different DO concentrations', Bioresource Technology. Elsevier Ltd, 100(14), pp. 3483-3488. doi: 10.1016/j.biortech.2009.02.059.

Herrero, M. and Stuckey, D. C. (2014) 'Bioaugmentation and its application in wastewater treatment: A review.', Chemosphere. Elsevier Ltd, 44. doi: 10.1016/j.chemosphere.2014.10.033.

Ikeda-Ohtsubo, W., Miyahara, M., Kim, S.-W., Yamada, T., Matsuoka, M., Watanabe, A., Fushinobu, S., Wakagi, T., Shoun, H., Miyauchi, K. and Endo, G. (2013) 'Bioaugmentation of a wastewater bioreactor system with the nitrous oxide-reducing denitrifier Pseudomonas 
731

732

733

734

735

736

737

738

739

740

741

742

743

744

745

746

747

748

749

750

751

752

753

754

755

756

757

758

759

stutzeri strain TR2.', Journal of bioscience and bioengineering. Elsevier Ltd, 115(1), pp. 3742. doi: 10.1016/j.jbiosc.2012.08.015.

Ikeda-Ohtsubo, W., Miyahara, M., Yamada, T., Watanabe, A., Fushinobu, S., Wakagi, T., Shoun, H., Miyauchi, K. and Endo, G. (2013) 'Effectiveness of heat treatment to protect introduced denitrifying bacteria from eukaryotic predatory microorganisms in a pilot-scale bioreactor.', Journal of bioscience and bioengineering. Elsevier Ltd, 116(6), pp. 722-4. doi: 10.1016/j.jbiosc.2013.05.024.

Jacques, R. J. S., Okeke, B. C., Bento, F. M., Teixeira, A. S., Peralba, M. C. R. and Camargo, F. A. O. (2008) 'Microbial consortium bioaugmentation of a polycyclic aromatic hydrocarbons contaminated soil', 99, pp. 2637-2643. doi: 10.1016/j.biortech.2007.04.047.

Jain, R. K., Sayler, G. S., Wilson, J. T., Houston, L. and Pacia, D. (1987) 'Maintenance and Stability of Introduced Genotypes in Groundwater Aquifer Material', Applied and environmental microbiology, 53(5), pp. 996-1002.

Jianlong, W., Xiangchun, Q., Libo, W., Yi, Q. and Hegemann, W. (2002) 'Bioaugmentation as a tool to enhance the removal of refractory compound in coke plant wastewater', Process Biochemistry, 38, pp. 777-781.

Khehra, M. S., Saini, H. S., Sharma, D. K., Chadha, B. S. and Chimni, S. S. (2005) 'Comparative studies on potential of consortium and constituent pure bacterial isolates to decolorize azo dyes.', Water research, 39(20), pp. 5135-41. doi: 10.1016/j.watres.2005.09.033.

Krhutková, O., Novák, L., Pachmanová, L., Benáková, A., Wanner, J. and Kos, M. (2006) ‘In situ bioaugmentation of nitrification in the regeneration zone: practical application and experiences at full-scale plants', Water Science \& Technology, 53(12), pp. 39-46. doi: 10.2166/wst.2006.404.

Van Limbergen, H., Top, E. M. and Verstraete, W. (1998) 'Bioaugmentation in activated sludge: current features and future perspectives', Applied Microbiology and Biotechnology, 50(1), pp. 16-23. doi: 10.1007/s002530051250.

Liu, X., Chen, Y., Zhang, X., Jiang, X., Wu, S., Shen, J., Sun, X., Li, J., Lu, L., Wang, L. (2015) 'Aerobic granulation strategy for bioaugmentation of a sequencing batch reactor 
760 (SBR) treating high strength pyridine wastewater.', Journal of Hazardous Materials. Elsevier 761 Ltd, 15(295), pp. 153-60. doi: 10.1016/j.jhazmat.2015.04.025.

762 Liu, C., Huang, X. and Wang, H. (2008) 'Start-up of a membrane bioreactor bioaugmented with genetically engineered microorganism for enhanced treatment of atrazine containing wastewater', Desalination, 231, pp. 12-19.

Ma, F., Guo, J., Zhao, L., Chang, C. and Cui, D. (2009) 'Application of bioaugmentation to improve the activated sludge system into the contact oxidation system treating petrochemical wastewater.', Bioresource technology. Elsevier Ltd, 100(2), pp. 597-602. doi: 10.1016/j.biortech.2008.06.066.

Mahin, A. A., Chowdhury, A. Z., Alam, M, K., Aktar, Z. and Fakhruddin, A. N. M. (2011) 'Phenol Biodegradation by Two Strains of Pseudomonas putida and Effect of Lead and Zinc on the Degradation Process', International Journal of Environment, 1, pp. 27-33.

Marañón, E., Vázquez, I., Rodríguez, J., Castrillón, L., Fernández, Y. and López, H. (2008) 'Treatment of coke wastewater in a sequential batch reactor (SBR) at pilot plant scale.', Bioresource Technology, 99(10), pp. 4192-8. doi: 10.1016/j.biortech.2007.08.081.

Martín-Hernández, M., Suárez-Ojeda, M. E. and Carrera, J. (2012) 'Bioaugmentation for treating transient or continuous p-nitrophenol shock loads in an aerobic sequencing batch reactor.', Bioresource technology, 123, pp. 150-6. doi: 10.1016/j.biortech.2012.07.014.

778 McClure, N. C., Fry, J. C. and Weightman, A. J. (1991) 'Survival and catabolic activity of 779 natural and genetically engineered bacteria in a laboratory-scale activated-sludge unit.', Applied and environmental microbiology, 57(2), pp. 366-73.

McClure, N. C., Weightman, A. J. and Fry, J. C. (1989) 'Survival of Pseudomonas putida

782 UWC1 containing cloned catabolic genes in a model activated-sludge unit.', Applied and 783 environmental microbiology, 55(10), pp. 2627-2634.

784 More, T. T., Yan, S., Tyagi, R. D. and Surampalli, R. Y. (2010) 'Review: Potential use of 785 filamentous fungi for wastewater sludge treatment.', Bioresource technology. Elsevier Ltd, 786 101(20), pp. 7691-7700. doi: 10.1016/j.biortech.2010.05.033. 
787 Nikolopoulou, M., Pasadakis, N. and Kalogerakis, N. (2013) 'Evaluation of autochthonous bioaugmentation and biostimulation during microcosm-simulated oil spills.', Marine pollution bulletin. Elsevier Ltd, 72(1), pp. 165-73. doi: 10.1016/j.marpolbul.2013.04.007.

790 Nublein, K., Maris, D., Timmis, K. and Dwyer, D. F. (1992) 'Expression and transfer of engineered catabolic pathways harbored by Pseudomonas spp . introduced into activated sludge microcosms.', Applied and environmental microbiology, 58(10), pp. 3380-86.

Obbard, J. and Shan, H. (2001) 'Ammonia removal from prawn aquaculture water using immobilized nitrifying bacteria', Applied Microbiology and Biotechnology, 57(5-6), pp. 791798. doi: 10.1007/s00253-001-0835-1.

796

Olaniran, A. O., Pillay, D. and Pilay, B. (2006) 'Biostimulation and bioaugmentation enhances aerobic biodegradation of dichloroethenes', Chemosphere, 63, pp. 600-608. doi: 10.1016/j.chemosphere.2005.08.027.

Onyia, C. O., Uyu, A. M., Akunna, J. C., Norulaini, N. A. and Omar, A. (2001) 'Increasing the fertilizer value of palm oil mill sludge: bioaugmentation in nitrification.', Water science and technology: a journal of the International Association on Water Pollution Research, 44(10), pp. 157-62. Available at: http://www.ncbi.nlm.nih.gov/pubmed/11794647.

803 Park, D., Lee, D. S., Kim, Y. M. and Park, J. M. (2008) 'Bioaugmentation of cyanide804 degrading microorganisms in a full-scale cokes wastewater treatment facility.', Bioresource 805 Technology, 99(6), pp. 2092-6. doi: 10.1016/j.biortech.2007.03.027.

806 Parker, D. and Wanner, J. (2007) 'Review of methods for improving nitrification through bioaugmentation', Water Practice, 1(5), pp. 1-16.

808 Philips, S., Laanbroek, H. J. and Verstraete, W. (2002) 'Origin, causes and effects of 809 increased nitrite concentrations in aquatic environments', Re/Views Environm Science \& 810 Bio/Technol, 1(2), pp. 115-141. doi: 10.1023/A:1020892826575.

811 Qu, Y., Zhang, R., Ma, F., Zhou, J. and Yan, B. (2011) 'Bioaugmentation with a novel alkali812 tolerant Pseudomonas strain for alkaline phenol wastewater treatment in sequencing batch 813 reactor', World Journal of Microbiology and Biotechnology, 27(8), pp. 1919-1926. doi: 814 10.1007/s11274-011-0653-2. 
815 Quan, X., Shi, H., Liu, H., Lv, P. and Qian, Y. (2004) 'Enhancement of 2,4-dichlorophenol 816 degradation in conventional activated sludge systems bioaugmented with mixed special 817 culture.', Water research, 38(1), pp. 245-53. doi: 10.1016/j.watres.2003.09.003.

818 Quan, X., Shi, H., Liu, H., Wang, J. and Qian, Y. (2004) 'Removal of 2,4-dichlorophenol in a 819 conventional activated sludge system through bioaugmentation', Process Biochemistry, 820 39(11), pp. 1701-1707. doi: 10.1016/S0032-9592(03)00307-8.

821 Ramadan, M. A., El-Tayeb, O. M. and Alexander, M. (1990) 'Inoculum size as a factor 822 limiting success of inoculation for biodegradation.', Applied and Environmental 823 Microbiology, 56(5), pp. 1392-6.

824 Salem, S., Berends, D. H. J. G., Heijnen, J. J. and Van Loosdrecht, M. C. M. (2003) 'Bio825 augmentation by nitrification with return sludge.', Water research, 37(8), pp. 1794-804. doi: $82610.1016 / \mathrm{S} 0043-1354(02) 00550-\mathrm{X}$.

827 Semrany, S., Favier, L., Djelal, H., Taha, S. and Amrane, A. (2012) 'Bioaugmentation: 828 Possible solution in the treatment of Bio-Refractory Organic Compounds (Bio-ROCs)', 829 Biochemical Engineering Journal. Elsevier B.V., 69, pp. 75-86. doi: $830 \quad$ 10.1016/j.bej.2012.08.017.

831 Shen, J., He, R., Yu, H., Wang, .L, Zhang, J., Sun, X., Li, J., Han, W., Xu, L. (2009) 832 'Biodegradation of 2,4,6-trinitrophenol (picric acid) in a biological aerated filter (BAF)', 833 Elsevier Ltd, 100(6), pp. 1922-30. 10.1016/j.biortech.2008.10.018.

834 Shoji, T., Sueoka, K., Satoh, H. and Mino, T. (2014) 'Identification of the microbial 835 community responsible for thiocyanate and thiosulfate degradation in an activated sludge 836 process', Process Biochemistry. Elsevier Ltd, 49(7), pp. 1176-1181. doi: 837 10.1016/j.procbio.2014.03.026.

838 Silva, Í. S., Santos, E. C., Menezes, C. R., Faria, A. F., Franciscon, E., Grossman, M. and 839 Durrant, L. R. (2009) 'Bioremediation of a polyaromatic hydrocarbon contaminated soil by 840 native soil microbiota and bioaugmentation with isolated microbial consortia', Bioresource 841 Technology. Elsevier Ltd, 100(20), pp. 4669-4675. doi: 10.1016/j.biortech.2009.03.079.

842 Smith, R. C., Saikaly, P. E., Zhang, K., Thomatos, S. and Oerther, D. B. (2008) 'Ecological 843 engineering of bioaugmentation from side-stream nitrification.', Water science and 
technology: a journal of the International Association on Water Pollution Research, 57(12), pp. 1927-33. doi: 10.2166/wst.2008.628.

Songzhe, F. U., Hongxia, F. A. N., Shuangjiang, L. I. U., Ying, L. I. U. and Zhipei, L. I. U. (2009) 'A bioaugmentation failure caused by phage infection and a weak biofilm formation ability', Journal of environmental sciences, 21, pp. 1153-1161.

Stephenson, D. and Stephenson, T. (1992) 'Bioaugmentation for enhancing biological wastewater treatment.', Biotechnology Advances, 10, pp. 549-59.

Stephenson, T. and Gerrard, A. M. (1990) 'A simple economic comparison of inoculum enhanced activated sludge processes', I.Chem.E. Symposium, 116, pp. 85-94.

Stephenson, T., Reid, E., Avery, L. M. and Jefferson, B. (2013) 'Media surface properties and the development of nitrifying biofilms in mixed cultures for wastewater treatment', Process Safety and Environmental Protection, 91(4), pp. 321-324. doi: 10.1016/j.psep.2012.07.002.

Stormo, K. E. and Crawford, R. L. (1992) 'Preparation of encapsulated microbial cells for environmental applications', Applied environmental microbiology, 58, pp. 727-730.

Straube, W. L., Nestler, C. C., Hansen, C. C., Ringleberg, L. D., Pritchard, P. H. and JonesMeehan, J. (2003) 'Remediation of Polyaromatic Hydrocarbons ( PAHs ) through Landfarming with Biostimulation and Bioaugmentation', Acta Biotechnology, 23(2-3), pp. $179-196$.

Stroo, H. F., Leeson, A. and Herb Ward, C. (2013) Bioaugmentation for Groundwater Remediation. New York: Springer Science.

Sun, G. D., Jin, J. H., Xu, Y., Zhong, Z. P., Liu, Y. and Liu, Z. P. (2014) 'Isolation of a high molecular weight polycyclic aromatic hydrocarbon-degrading strain and its enhancing the removal of HMW-PAHs from heavily contaminated soil', International Biodeterioration and Biodegradation. Elsevier Ltd, 90, pp. 23-28. doi: 10.1016/j.ibiod.2014.01.020.

Teng, Y., Luo, Y., Sun, M., Liu, Z., Li, Z. and Christie, P. (2010) 'Effect of bioaugmentation by Paracoccus sp . strain HPD-2 on the soil microbial community and removal of polycyclic 
871

872

873

874

875

876

877

878

879

880

881

882

883

884

885

886

887

888

889

890

891

892

893

894

895

896

897

898

aromatic hydrocarbons from an aged contaminated soil', Bioresource Technology. Elsevier Ltd, 101(10), pp. 3437-3443. doi: 10.1016/j.biortech.2009.12.088.

Thompson, I. P., van der Gast, C. J., Ciric, L. and Singer, A. C. (2005) 'Bioaugmentation for bioremediation: the challenge of strain selection.', Environmental microbiology, 7(7), pp. 909-15. doi: 10.1111/j.1462-2920.2005.00804.x.

Torres, B., Garcia, J. and Diaz, E. (2003) Plasmids as tools for containment. In Funnell B, Phillips G(eds) Plasmid Biology. Washington: ASM Press.

Tyagi, M., da Fonseca, M. M. R. and de Carvalho, C. C. C. R. (2011) 'Bioaugmentation and biostimulation strategies to improve the effectiveness of bioremediation processes.', Biodegradation, 22(2), pp. 231-41. doi: 10.1007/s10532-010-9394-4.

Ueno, A., Ito, Y., Yumoto, I. and Okuyama, H. (2007) 'Isolation and characterization of bacteria from soil contaminated with diesel oil and the possible use of these in autochthonous bioaugmentation', World Journal of Microbiology and Biotechnology, 23(12), pp. 17391745. doi: 10.1007/s11274-007-9423-6.

US.EPA (2015) Summary of the Clean Water Act. Available at: https://www.epa.gov/lawsregulations/summary-clean-water-act (Accessed: 20 August 2016).

Vidal, G., Carvalho, A., Méndez, R. and Lema, J. M. (2000) 'Influence of the content in fats and proteins on the anaerobic biodegradability of dairy wastewaters', Bioresource Technology, 74(3), pp. 231-239. doi: 10.1016/S0960-8524(00)00015-8.

Vogel, T. M. (1996) 'Bioaugmentation as a soil bioremediation approach.', Current opinion in biotechnology, 7(3), pp. 311-6.

Wanner, J., Cech, J. S., Kos, M. and Barchanek, M. (1996) 'Municipal effluent standards in the Czech Republic', Water Science \& Technology, 33(12), pp. 1-10.

Wanner, J., Kos, M. and Novák, L. (2009) 'Intensification of Prague Central WWTP - Ten years of practical experiences with the in-situ bioaugmentation nitrification method', Technology, 4(1), pp. 1-8. doi: 10.2166/WPT.2009.016.

Wenderoth, D. F., Rosenbrock, P., Abraham, W.-R., Pieper, D. H. and Höfle, M. G. (2003) 'Bacterial community dynamics during biostimulation and bioaugmentation experiments 
899 aiming at chlorobenzene degradation in groundwater', Microbial Ecology, 46(2), pp. 161900 176. doi: 10.1007/s00248-003-2005-8.

901 Yu, K. S. H., Wong, a H. Y., Yau, K. W. Y., Wong, Y. S. and Tam, N. F. Y. (2005) 'Natural

902 attenuation, biostimulation and bioaugmentation on biodegradation of polycyclic aromatic 903 hydrocarbons (PAHs) in mangrove sediments.', Marine pollution bulletin, 51(8-12), pp. 904 1071-7. doi: 10.1016/j.marpolbul.2005.06.006.

905 Yu, L., Peng, D. and Pan, R. (2012) 'Shifts in nitrification kinetics and microbial community 906 during bioaugmentation of activated sludge with nitrifiers enriched on sludge reject water.', 907 Journal of biomedicine \& biotechnology, 2012, p. 691894. doi: 10.1155/2012/691894.

908 Yu, L., Peng, D. and Ren, Y. (2011) 'Protozoan predation on nitrification performance and 909 microbial community during bioaugmentation.', Bioresource technology. Elsevier Ltd, 910 102(23), pp. 10855-60. doi: 10.1016/j.biortech.2011.09.060.

911 Zhang, J., Wen, D., Zhao, C. and Tang, X. (2014b) 'Bioaugmentation accelerates the shift of 912 bacterial community structure against shock load: a case study of coking wastewater 913 treatment by zeolite-sequencing batch reactor.', Applied microbiology and biotechnology, 914 98(2), pp. 863-73. doi: 10.1007/s00253-013-4848-3.

915 Zhang, X., Li, X., Zhang, Q., Peng, Q., Zhang, W. and Gao, F. (2014a) 'New insight into the 916 biological treatment by activated sludge: The role of adsorption process.', Bioresource 917 technology. Elsevier Ltd, 153, pp. 160-4. doi: 10.1016/j.biortech.2013.11.084. 